\title{
Examination of consistency of marine gravity with land gravity in and around the Japanese Islands using a helicopter-borne gravimeter
}

\author{
Jiro Segawa ${ }^{1}$, Masao Komazawa ${ }^{2}$, K. Vijay Kumar ${ }^{1}$, Eiji Nakayama ${ }^{3}$, E. John Joseph ${ }^{4}$, \\ Shigekazu Kusumoto $^{1}$, Ken-ei Onodera ${ }^{5}$, and Yuki Kuroishi ${ }^{6}$ \\ ${ }^{1}$ School of Marine Science and Technology, Tokai University, 3-20-1 Shimizu-Orido, Shizuoka 424-8610, Japan \\ ${ }^{2}$ Geological Survey of Japan, National Institute of Advanced Industrial Science and Technology, \\ 1-1-1 C\#7 Higashi, Tsukuba, Ibaraki 305-8567, Japan \\ ${ }^{3}$ AeroGRAV, 1-44-5-206 Bessho, Hachioji, Tokyo 192-0363, Japan \\ ${ }^{4}$ Geology and Geophysics, School of Earth and Environmental Sciences, the University of Adelaide, SA 5005, Australia \\ ${ }^{5}$ Hydrographic and Oceanographic Department, Japan Coast Guard, 5-3-1 Tsukiji, Chuo-ku, Tokyo 104-0045, Japan \\ ${ }^{6}$ Geographical Survey Institute, 1 Kitasato, Tsukuba, Ibaraki 305-0811, Japan
}

(Received July 9, 2004; Revised February 28, 2005; Accepted March 1, 2005)

\begin{abstract}
This paper reports a finding that marine gravity data around the Japanese Islands are inconsistent with nearby land gravity data. The comparison between land and marine gravity was made possible by the gravity measurements from the air using a helicopter-borne gravimeter (SEGAWA Model) developed by the present authors. The ground/sea truth gravity anomaly can be checked against the gravity from the air, though it is not free air gravity anomaly but gravity disturbance. The newly-developed airborne gravimeter first manufactured in 1998 shows a good performance with a 1-2 mgal average repeatability of measurement under a 90-knot flight speed. Thus we have found disagreements between ground truth and sea truth gravity anomalies on the basis of airborne gravity data in the areas in Japan where we have so far made measurements. Among them we will report the case in the area from Saitama and Ibaraki offshore to the Kashima-Nada Sea, Japan. Our conclusion about this area is that the past marine gravity data obtained by surface ship gravimeters involve systematic errors of more than 10 mgals. This kind of inconsistency between marine and land gravity is expected to be found in a number of other areas around the Japanese Islands.
\end{abstract}

Key words: Inconsistency between marine and land gravity, helicopter-borne gravimeter.

\section{Introduction}

Practical measurements of gravity at sea were initiated by Vening Meinesz (1929, 1941). He conducted gravity measurements by his 'Triplet pendulums' on board submarines to avoid sea waves. Surface ship gravity measurements followed in 1960's using newly-designed gravimeters such as the LaCoste \& Romberg Air-Sea Gravimeter (LaCoste, 1959, 1967b; LaCoste et al., 1967a), the Askania Gss (Graf, 1958; Graf and Schulze, 1961), TSSG (Tsuboi et al., 1961; Tomoda and Kanamori, 1962) and so on. Thus the marine gravity measurements were made in most part of the sea in the world by many ships and operators. There are two problems, however, in marine gravity measurement: Large errors in ship's positioning which affects gravity data seriously, and no after-care about the gravity data once obtained. Since it is very laborious and costly to make gravity measurement at sea, few survey cruises have repeated measurements at the same survey areas in order to confirm the results. The land gravity data, on the other hand, has a very solid background in various points and, with the aid of rapid instrumental progress, they maintain the reliability far better than that of the marine data.

Copy right(c) The Society of Geomagnetism and Earth, Planetary and Space Sciences (SGEPSS); The Seismological Society of Japan; The Volcanological Society of Japan; The Geodetic Society of Japan; The Japanese Society for Planetary Sciences; TERRAPUB.
At present the marine gravity data have been accumulated both by surface ship measurements and by radar altimetry from artificial satellite (Sandwell and Schubert, 1982, for instance). The airborne gravity measurement developed since 1990's, on the other hand, was applied to obtain gravity data in the gravity void zones, such as Antarctica or Greenland (Brozena et al., 1990; Brozena, 1992). In the case of the Japanese Islands gravity has been extensively surveyed on land as well as at sea within territorial waters and the 200 nautical mile-economic zones. Gravity data on land were collected using mostly the LaCoste \& Romberg G or D type gravimeters by the Geographical Survey Institute of Japan (GSI), the Geological Survey of Japan (GSJ) and several groups from universities in Japan. Marine gravity data were collected mostly by the Hydrographical Department of Japan (now renamed as Hydrographic and Oceanographic Department of Japan (HOD)), GSJ, the Japan Marine Science and Technology Center (JAMSTEC) and the Ocean Research Institute, University of Tokyo (ORI). In addition the marine gravity includes those measured by foreign survey ships which cruised around the Japanese Islands. These Japanese and foreign data are collected and summarized by Bureau Gravimetrique Internationale in Paris (BGI), which provides well sorted gravity data for the users.

Contrary to the land gravity data the marine gravity data 


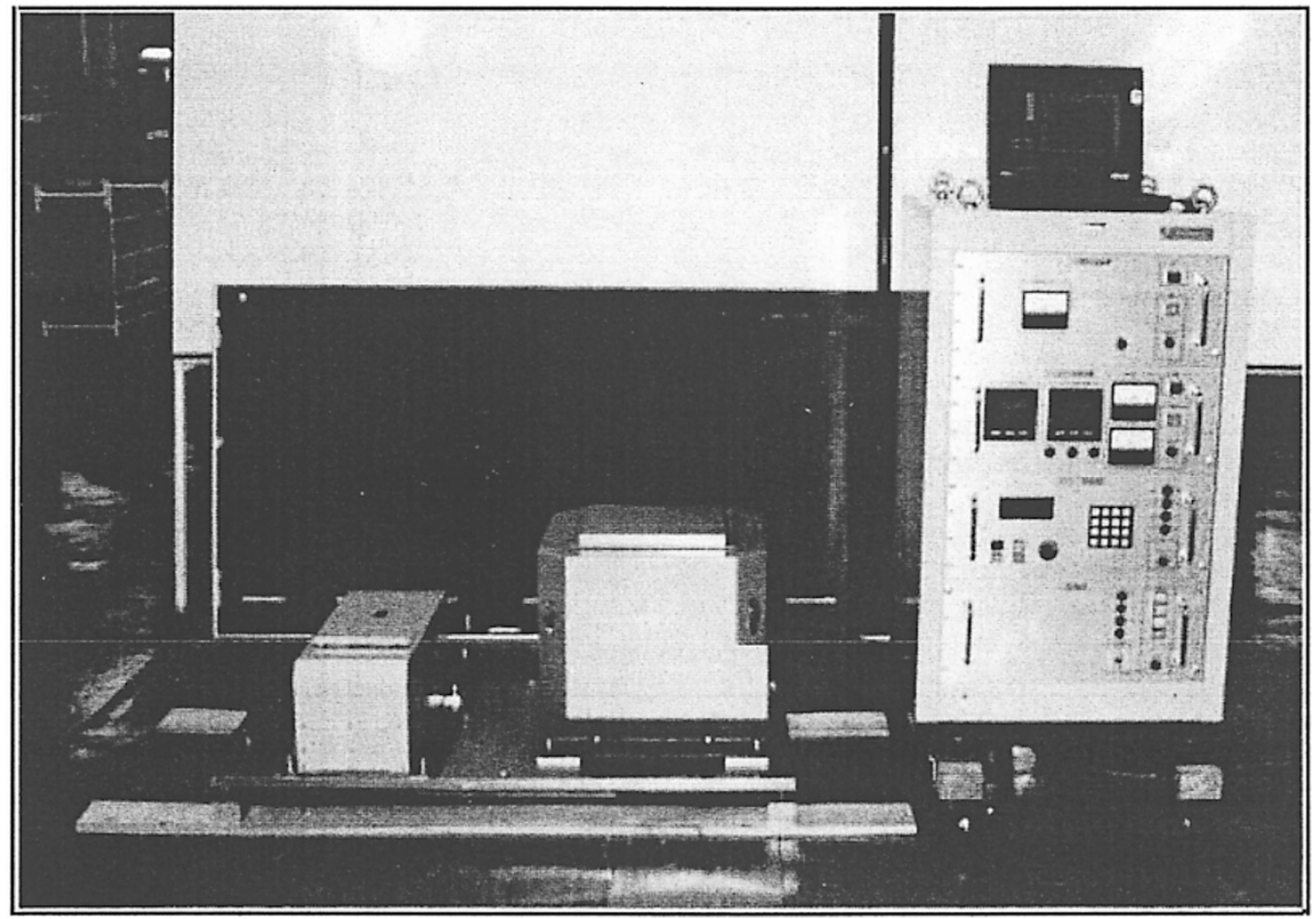

Fig. 1. The outer view of helicopter-borne gravimeter (SEGAWA Model). The tall cabinet in the right side is controllers of gravimeter including a power supply. On the top of the cabinet is installed a personal computer which records gravity data and works as an analog monitor. In the center is the gravity sensor mounted on a gyro-stabilized platform. In the left side is an optical fiber gyro to control the stabilized platform. Total weight of the assembly is about $200 \mathrm{~kg}$.

are subjected to unnegligible errors particularly with regard to the data obtained before 1985 when GPS was not available. Marine gravity measurements are affected by ship's positioning in two ways; one is the wrong position of measurement itself and the other the Eötvös correction error due to inaccuracy in the estimation of ship's speed. Although the accuracy of marine gravity have been gradually enhanced after the advent of GPS, many gravity data from old marine surveys still remain as they were and are likely to be used for geodetic or geophysical purposes without knowing the problem of the data. It seems very difficult to harmonize land and marine gravity measurements because the organizations conducting surveys are quite different between land and sea.

It is true that Japan is the area where gravity was well surveyed, but no one has ever examined the consistency of marine gravity with land gravity. To execute such examinations it is desirable to measure gravity across the land-tosea boundary - it is the airborne gravimetry that will make it possible.

\section{Helicopter Gravimeter}

The gravimeter we have developed is 'SEGAWA Model (FGA-1)' designed to be used on board a helicopter. The gravimeter for helicopter use was also developed by Gumert and Cobb (1970) and Hammer (1983). But, these pioneering works seem to have had much difficulty in positioning as GPS was not available.

Helicopter or Fixed-wing aeroplane: There are two sources from which the airborne gravimetry has developed. One is to use a fixed-wing aeroplane and the other is to use a helicopter. In the case of the first test of gravity measurement in the air (Thompson, 1959; Thompson and LaCoste, 1960) a fixed-wing aeroplane and a LaCoste \& Romberg Air-Sea Gravimeter were used. Demerit of the fixed-wing aeroplane from the viewpoint of gravity measurement is that it generates extraordinary accelerations in case of takeoff or landing, that it flies too fast on a too high level, resulting in deterioration of gravity resolution, and that it needs a large airport. The authors of this paper once tried a Cessna for the aerial gravity measurements during the first stage of this study, but later changed to a helicopter which can adjust the speed and altitude of flight and take off from a small heliport. At first we were anxious about the vibration noises and the interference of the rotating blades with GPS radio signals. But these problems were overcome and, at present, we use a helicopter for the surveys and fly usually at a 90-knot stable speed at the altitude of 2000-3000 ft. (The largest problem with the helicopter is that it is expensive, though).

Segawa Model: Although details of SEGAWA Model are described in Segawa et al. (2000a, b), its brief explanation is also given here. This gravimeter consists of a servo accelerometer type gravity sensor (TGA109), a gyro stabilized platform (SP120), an optical fiber gyro (FMS-1), controllers, data processors and power supply. The gravity sensor has a resolution of $0.01 \mathrm{mgal}$ with sampling interval of $0.01 \mathrm{sec}$. The verticality of gyro stabilized platform is within a $3^{\prime}$ of arc. The optical fiber gyro is of the strapdown type which maintains the vertical on the basis of latitude, longitude and altitude provided from GPS. At the starting time the gyro swings under Schuler's principle but it decays 


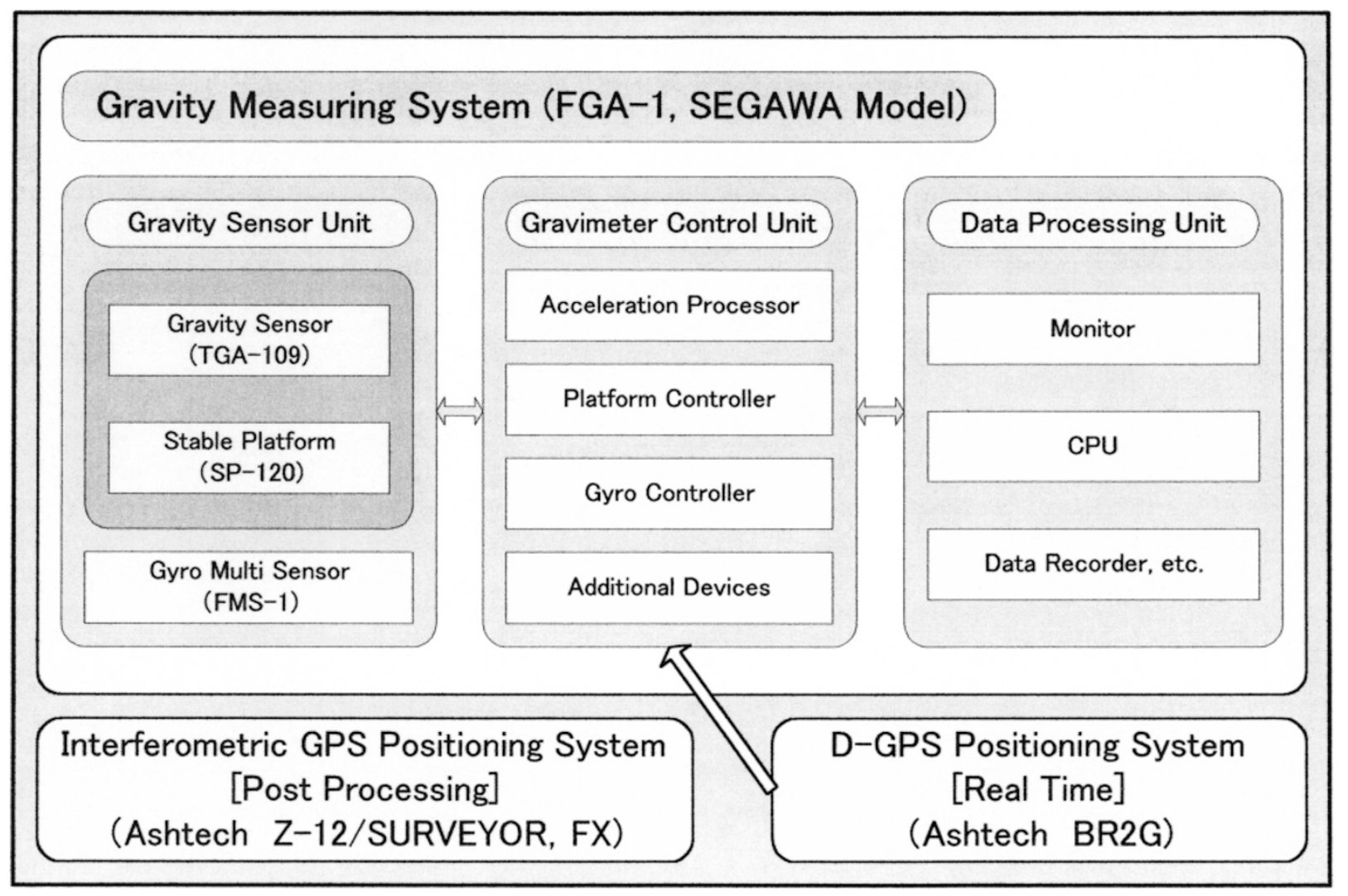

Fig. 2. A block diagram of the Gravity Measuring System (SEGAWA Model). The system consists of Gravity Sensor Unit, Gravimeter Control Unit, and Data Processing Unit. To assist the operation there is Interferometric GPS Positioning System for post processing and DGPS Positioning System for real time processing.

in two hours or so and becomes stable. This type of gyro is free from drift because its posture is maintained by resetting 3-dimensional position in real time based on DGPS. The outer view of the gravimeter is shown in Fig. 1. Figure 2 shows a block diagram of the assembly of the gravity measuring system, and Fig. 3 shows a flow chart of data processing. The values to be obtained are gravity plus helicopter acceleration measured by the gravity sensor together with a pair of horizontal accelerometers and, 3-dimensional position and speed measured by GPS. There are two GPS receivers on board a helicopter, one for interferometric positioning by post processing and the other for the DGPS based on pseudo-range measurement for real time positioning. The DGPS system around Japan is maintained by the Japan Coast Guard. The interferometric GPS positioning data are used for precise vertical and horizontal acceleration corrections including the Eötvös correction, and the DGPS positioning data are provided as the basic data for the strapdown type optical fiber gyro (gyro multi sensor) in real time. In Fig. 4 is shown the gravimeter system installed on a helicopter Bell 412.

The gravimeter on board a helicopter outputs acceleration data every $0.1 \mathrm{sec}$, which are averages of ten 0.01 sec-data. The horizontal accelerometers are attached to the gyro-stabilized platform, each aligning in the nose direction and the direction perpendicular to it. The horizontal accelerations are obtained every $1 \mathrm{sec}$, which are used to calculate horizontal acceleration corrections by combining them with GPS data (this is referred to again later). The
GPS data are also obtained every $1 \mathrm{sec}$. The Eötvös correction is applied according to Harlan (1968). The optical fiber gyro (FMS-1) used is mechanically connected to the stable platform whose posture follows the vertical indicated by the gyro. The unit with a gravity sensor, a stable platform and a gyro combined together is detached from the helicopter floor to avoid vibrations.

To all the acceleration data is uniformly applied a digital low pass filter. The digital low pass filter is of the form of either Gaussian function or Cosine type function with a half spread of $150 \mathrm{sec}$ or shorter.

On the altitude of the aerial gravity measurement: In the airborne gravimetry a special attention has to be paid to the height of measurement. In the flat field we usually fly at the altitude of $2000 \mathrm{ft}(609.6 \mathrm{~m})$ according to the barometric altimeter. But this altimeter is used as a very rough indicator, so that the actual flight altitude is measured by GPS separately. The altitude obtained from GPS is the altitude above the Reference Ellipsoid WGS84. We understand that the WGS84 Ellipsoid is almost the same as the Normal Ellipsoid based on the Geodetic Reference System 1980 proposed by IUGG/IAG. In Fig. 5 is shown a geometric relationship between Normal Ellipsoid, geoid and helicopter flight level, where the ellipsoidal height (the height above the Ellipsoid) of helicopter flight level is denoted by $h_{e}$, the height of geoid by $h_{g}$, the Normal Gravity on the Normal Ellipsoid by $\gamma_{e}$, gravity on the geoid by $g_{h g}$ and gravity on the flight level by $g_{h e}$. For the sake of comparison between airborne gravity and ground/sea truth gravity it 


\section{Data Processing}

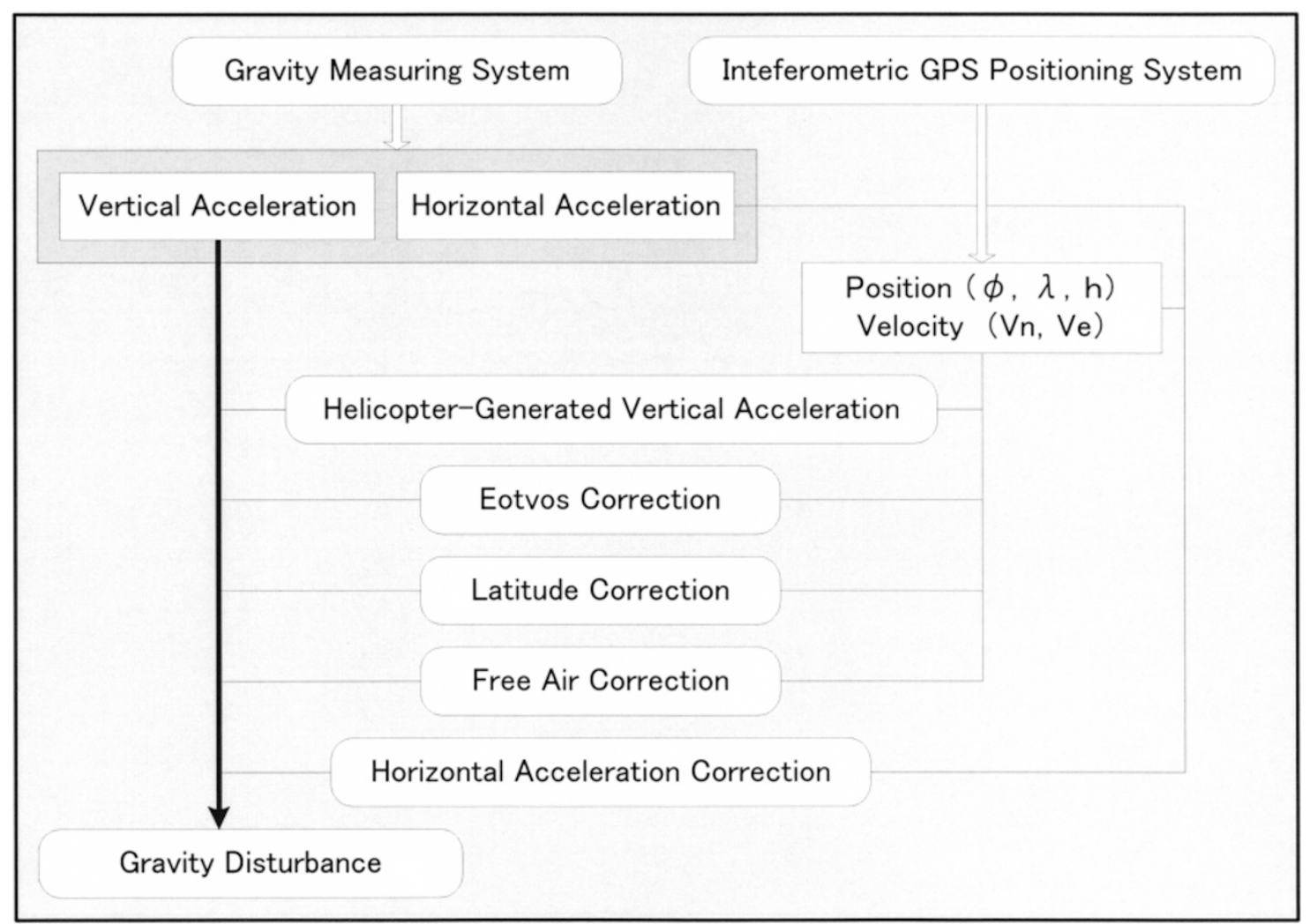

Fig. 3. A flow chart of data processing. There are three basic data sources: Vertical and horizontal accelerations from the gravity measuring system, and position/velocity from the interferometric GPS positioning system. From these data the gravity disturbance at the level of measurement defined by Ellipsoidal Height is derived.

may be common to convert the airborne gravity to the corresponding gravity on the geoid. But we did not take such a procedure because the downward continuation of gravity is likely to exaggerate short wavelength gravity errors. Since the airborne gravity data are measured at the level whose altitude is defined by ellipsoidal height, the gravity anomaly finally obtained is not free air gravity anomaly but gravity disturbance. So, we took a reverse way, i.e. we first convert the ground/sea truth free air gravity anomaly on the geoid to gravity disturbance on the Ellipsoid by applying the 'correction for the height of geoid'. The model of the height of geoid around Japan has recently been well studied and published by papers such as GSIGEO2000 model (Kuroishi et al., 2002). Using this sort of geoid model we get ground/sea truth gravity disturbances on the Normal Ellipsoid and then we apply the upward continuation processing to the ground/sea truth data to get ground/sea truth gravity disturbance continued on the helicopter flight level. The procedure to make a comparison between airborne gravity and ground/sea truth gravity will be summarized as follows:

1) The primary gravity anomaly obtained from airborne gravity measurement is gravity disturbance. The height of measurement is expressed by ellipsoidal height (the height above the Normal Ellipsoid). The flight level of helicopter is subject to change but the ellipsoidal height $2000 \mathrm{ft}$ $(609.6 \mathrm{~m})$ is normally chosen for the case of measurement in the flat areas. If gravity at the flight level is expressed by $g_{h e}$ then the gravity disturbance on site $\delta g_{h e}$ is expressed by

$$
\delta g_{h e}=g_{h e}-\left(\gamma_{e}-0.3086 h_{e}\right)
$$

where $\gamma_{e}$ is the normal gravity on the Normal Ellipsoid. The co-efficient $0.3086 \mathrm{mgal} / \mathrm{m}$ is the zeroth-order gravity gradient of the normal gravity $\gamma_{e}$.

2) If the ground/sea truth gravity on the geoid is expressed by $g_{h g}$ then the free air gravity anomaly on the geoid $\Delta g_{h g}$ is expressed by

$$
\Delta g_{h g}=g_{h g}-\gamma_{e} \text { according to the definition. }
$$

The gravity disturbance on the Normal Ellipsoid $\delta g_{h g}$ for the ground/sea truth data, on the other hand, can be expressed by

$$
\delta g_{h g}=\Delta g_{h g}+0.3086 h_{g}=g_{h g}-\gamma_{e}+0.3086 h_{g}
$$

where $h_{g}$ is the height of geoid. Since $h_{g}$ varies from place to place with the amplitude of roughly a few tens of meter the ground/sea truth gravity disturbance changes differently from the ground/sea truth free air gravity anomaly. Now, after this sort of consideration we will compare airborne gravity disturbance on the flight level with the ground/sea truth gravity disturbance. In order to convert ground/sea truth gravity disturbance on the Normal Ellipsoid to that on the helicopter flight level, we have to apply the inverse 

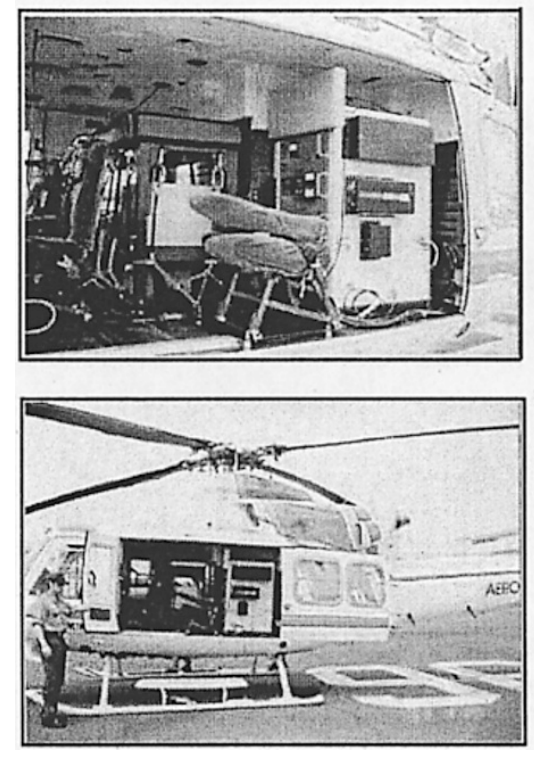

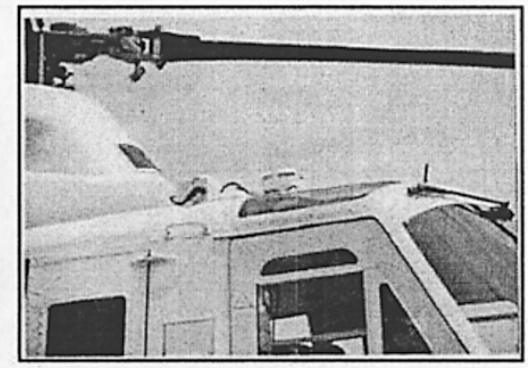

HELICOPTER-MOUNTED

GRAVIMETER SYSTEM

FGA-1, Ver.2003

(SEGAWA Model)

Fig. 4. The helicopter-borne gravimeter mounted on Bell 412 helicopter. Upper left shows the main part of the gravimeter installed inside the passengers' room by replacing chairs. Upper right shows GPS antennas mounted on the roof of helicopter just below the rotating blades. Lower left shows the outer view of the helicopter.

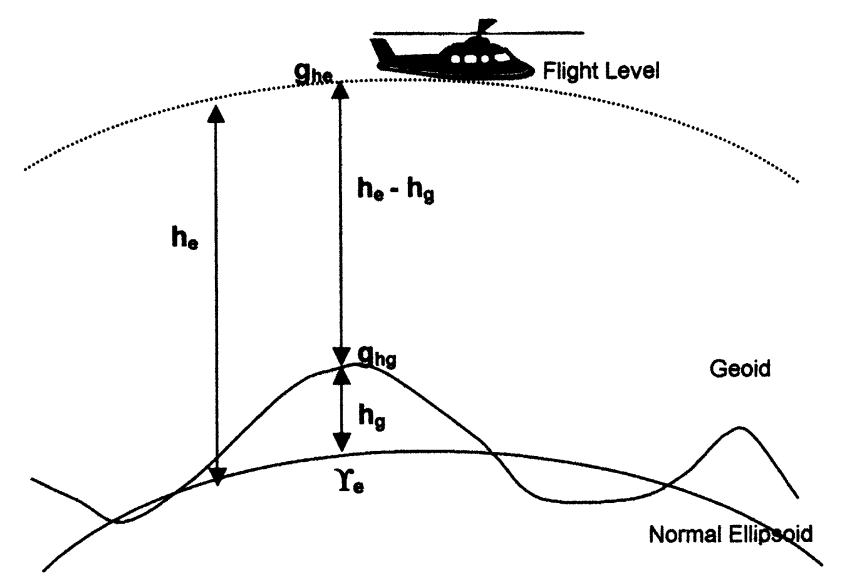

Fig. 5. Relationship between Normal Ellipsoid, geoid and helicopter flight level for gravity measurement. $h_{e}, h_{g}, \gamma_{e}, g_{h g}$ and $g_{h e}$ denote Ellipsoidal height of flight level, height of geoid, Normal Gravity on the Ellipsoid, gravity on the geoid and gravity on the flight level, respectively.

free air reduction $\left(-0.3086 h_{e}\right)$ and the upward continuation dependent on the wavelengths of gravity anomaly. The ground/sea truth gravity data compiled by M. Komazawa (Personal Communication) based on GSJ and HOD measurements have undergone smoothing operation to suppress abnormal changes of gravity so that their minimum wavelength seems to be longer than 2 nautical miles $(3.7 \mathrm{~km})$. So, it is expected that the upward continuation on the level $2000 \mathrm{ft}(609.6 \mathrm{~m})$ high would not cause any significant attenuation of gravity anomaly.

Horizontal acceleration correction: Here we will give a special comment on the horizontal acceleration correction because it is crucial for the airborne gravity measurement. Horizontal acceleration errors are caused by horizontal acceleration of helicopter when there is a deflection of the sensor vertical. This sort of error affects the gravity value

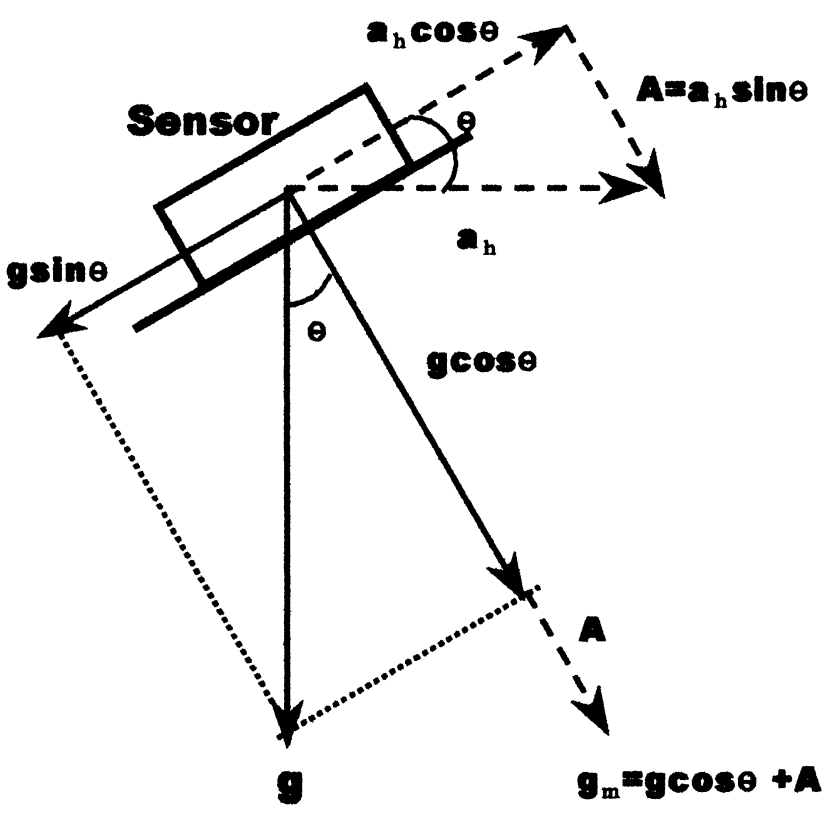

Fig. 6. A schematic figure to show the vectors of force which cause the horizontal acceleration error. $g, \theta$ and $a_{h}$ are gravity, deflection of the vertical of the gravimeter platform and horizontal acceleration, respectively. See text for further description.

with the amount of a few tens of mgal even after it is filtered. So, this must be removed by a proper correction. In Fig. 6 are shown schematically the vectors of force acting on the gravity sensor and the horizontal accelerometer in the two dimensional case. When the measuring axis of gravity sensor is deflected by $\theta$ from the vertical under the forces of gravity $g$ and horizontal acceleration $a_{h}$, the total acceleration $g_{m}$ sensed by gravity sensor is expressed by $g_{m}=g \cos \theta+a_{h} \sin \theta$. The horizontal acceleration $a_{h}$ is obtained from the time-derivative of GPS position changes. The acceleration $a_{m}$ sensed by the horizontal accelerometer 


\section{April 2000 Gravity Survey}

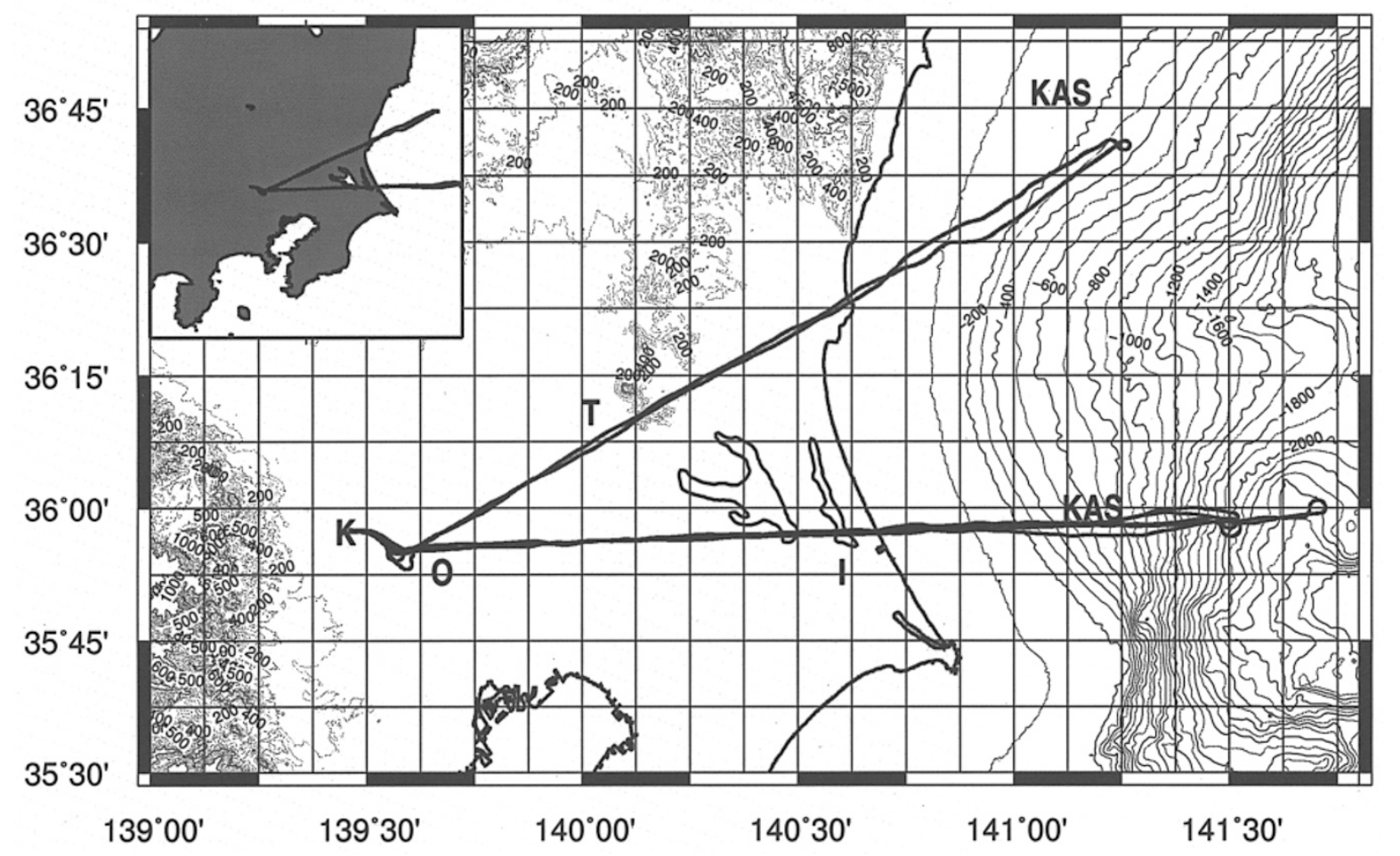

Fig. 7. Location and tracks of helicopter in the case of gravity measurements from 25 to 27 April, 2000 in Saitama, Ibaraki and the Kashima-Nada Sea, Japan. Three round track measurements were conducted in almost the same west-to-east direction across the coast of the Kashima-Nada Sea. Another track was flown in the south-west to north-east direction across Mt. Tsukuba. The Kawagoe heliport was used in this case. K: Kawagoe heliport O: Omiya I: Ibaraki Pref. KAS: Kashima-Nada Sea T: Mt. Tsukuba.

is, on the other hand, expressed by $a_{m}=-g \sin \theta+a_{h} \cos \theta$ ( $a_{m}$ is not displayed in Fig. 6). From these two relationships we can evaluate the deflection angle $\theta$, hence the correction to evaluate the true gravity. The algorithm is summarized as follows:

If $\theta$ is as small as $\theta^{3}$ or higher degree terms are neglected, $a_{m}$ is expressed by a quadratic equation of $\theta$ as, $a_{m}=$ $-g \theta+a_{h}\left(1-\theta^{2} / 2\right)$. From this equation an approximate value of $\theta$ can be obtained as $\theta=\left\{-g+\left[g^{2}+2 a_{h}\left(a_{h}-\right.\right.\right.$ $\left.\left.\left.a_{m}\right)\right]^{1 / 2}\right\} / a_{h}$, and the horizontal acceleration correction $\delta H$ is obtained as, $\delta H=g-g_{m}=-a_{h} \theta+g \theta^{2} / 2$.

There is a problem in the equation representing the relationship between $\theta$ and $a_{h}$, i.e., the equation is singular when $a_{h}$ is zero. So, we apply Taylor's expansion to the equation up to degrees 2 , as $\theta=\left(a_{h}-a_{m}\right) / g-\left(a_{h} / 2 g\right)\left(a_{h}-\right.$ $\left.a_{m}\right)^{2} / g^{2}$. By this expansion we find the singularity of the equation has disappeared. Since $\left|\left(a_{h}-a_{m}\right) / g\right|$ and $\left|a_{h} / 2 g\right|$ is less than unity the first term in the right hand side formula is much larger than the second term. So, as the first approximation, we put $\theta^{*}=\left(a_{h}-a_{m}\right) / g$, and rewrite the above formula as

$$
\theta=\theta^{*}-\left(a_{h} / 2 g\right)\left(\theta^{*}\right)^{2} .
$$

Now, putting $\theta$ to the formula of $\delta H$, we have an approximate formula as

$$
\delta H=-a_{h} \theta^{*}+\left(g^{2}+a_{h}^{2}\right)\left(\theta^{*}\right)^{2} /(2 g)
$$

Considering the deflection of the vertical with the present stable platform is within a $3^{\prime}$ of arc, $\left|\theta^{*}\right|$ may be less than
$10^{-3}$ radian. So, the first term of the above formula $\left|-a_{h} \theta^{*}\right|$ may be less than $50 \mathrm{mgal}$ for the case when $a_{h}$ is less than $50 \mathrm{gal}$, and the second term $\left(g^{2}+a_{h}^{2}\right)\left(\theta^{*}\right)^{2} /(2 g)$ may be less than $0.5 \mathrm{mgal}$ under the same condition.

\section{Comparison of Airborne Gravity with Ground/sea Truth Gravity-A Case in the Kashima-Nada Sea}

We have been conducting reconnaissance as well as practical measurements of gravity using helicopter (Bell 412) since 1999, and in 2000 we became confident about the accuracy of our helicopter gravity measurement for practical use.

From 25 through 27 April 2000, we made gravity measurements in the area from Saitama and Ibaraki offshore to the Kashima-Nada Sea, Japan. As seen from Fig. 7 we first repeated three round track measurements along the same west-to-east course, departing from Kawagoe Heliport of Saitama Prefecture, once visiting Omiya, then passing Ibaraki Prefecture and crossing the coast to the Kashima-Nada Sea (Flight 1 through 3. Flight 4 was abandoned due to bad weather). After this measurement we flied northeastwards, passing Mt. Tsukuba and to the KashimaNada Sea (Flight 5). Flight speed is about 90 knots, and flight altitude is $2000 \mathrm{ft}$. The three tracks in the west-toeast direction were the same with each other. This was done intentionally so that the repeatability of the measurement can be examined. The three round tracks, however, did not 


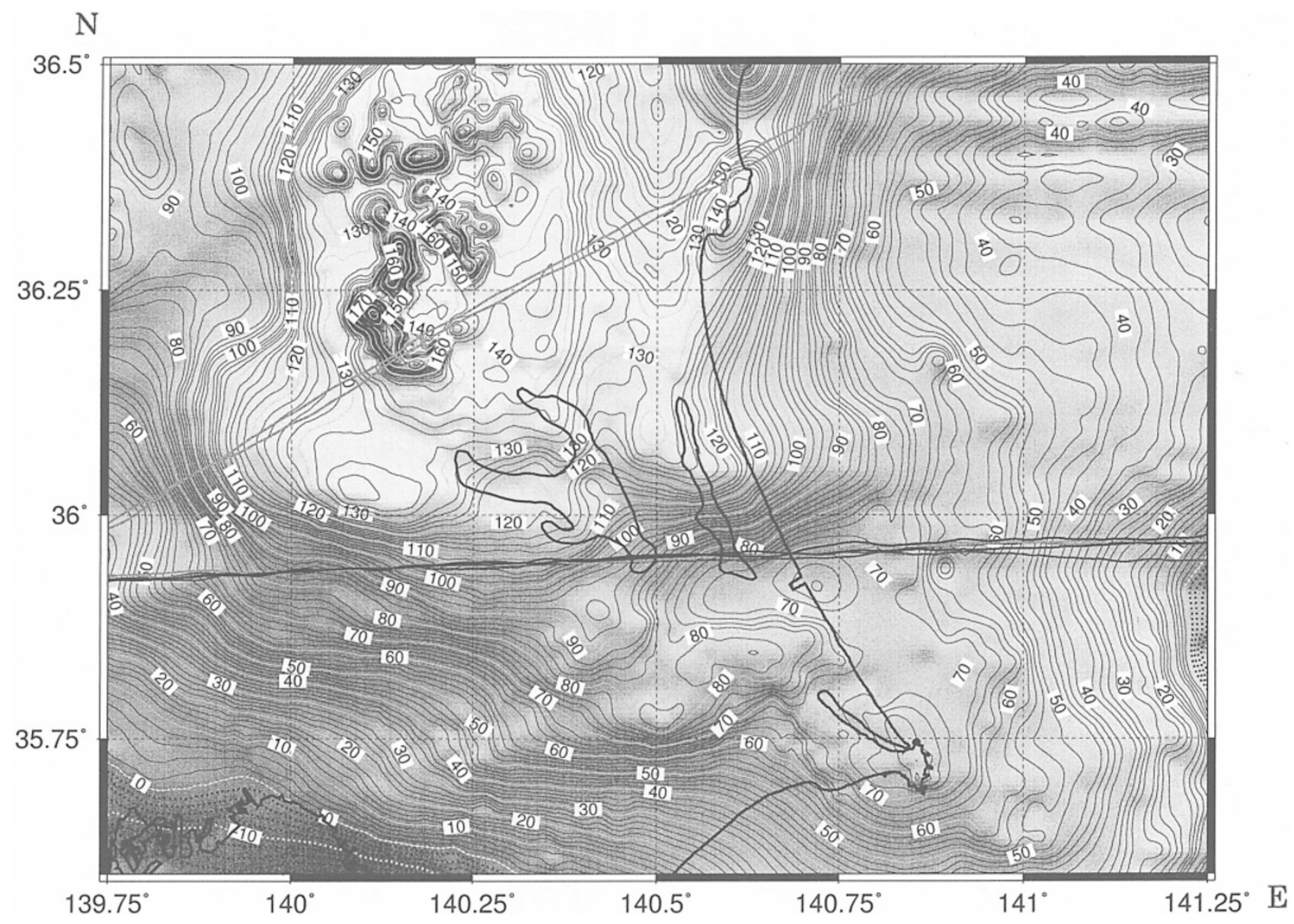

Fig. 8. Free air gravity anomaly in the Kashima-Nada Sea and the surroundings. This map is prepared to show a general view of gravity anomaly in this area. Contour interval is 2 mgal. This map is based on GSJ $1 \mathrm{~km}-\mathrm{by}-1 \mathrm{~km}$ mesh data arranged on the basis of GSJ and HOD data (M. Komazawa, Personal communication). Gravity anomaly is going down to the east toward the Japan trench.

agree in their eastern portions (above the sea) due to the radio navigation problem (In this case piloting was done by radio guidance, not by GPS). The offset of the tracks, however, is less than 3 nautical miles.

The Kawagoe Heliport is a private one maintained by Aero Asahi Corporation. The elevation above the sea level, the height of the geoid and free air gravity anomaly at the take-off site $\left(35^{\circ} 57.51^{\prime} \mathrm{N}, 139^{\circ} 28.07^{\prime} \mathrm{E}\right)$ is $14 \mathrm{~m}, 39.8 \mathrm{~m}$ and $40 \mathrm{mgal}$, respectively. These values were used for calibration.

Before discussing details of gravity data a comment on the general view of gravity and geoid in this area will be given. Figure 8 shows a map of free air gravity anomaly in the Kashima-Nada Sea and the surroundings. This map is contoured with the interval of 2 mgal using gravity data compiled by GSJ. The contouring is based on $1 \mathrm{~km}-$ by- 1 $\mathrm{km}$ mesh data arranged from the GSJ and the HOD raw data (Miyazaki, 1984; Ganeko et al., 1981; M. Komazawa, personal communication). The distribution of raw gravity data is not uniform, the spacing of the points of measurement on land being from 0.5 to a few nautical miles. The gravity data at sea, on the other hand, align the parallel ship's tracks with the spacing of about 2 nautical miles. Figure 9 shows a contoured map of geoid (GSIGEO2000) on the Normal Ellipsoid 1980 in the Kashima-Nada Sea and the surroundings (Kuroishi et al., 2002). The contour interval is $20 \mathrm{~cm}$.

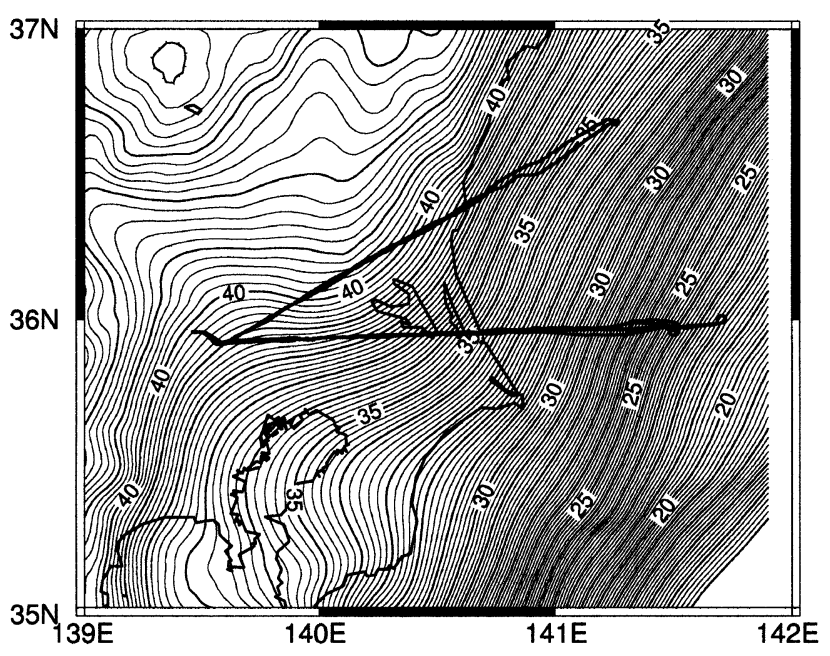

Fig. 9. Geoid map GSIGEO2000 of the Kashima-Nada Sea and the surroundings after Kuroishi et al. (2002). Contour interval is $20 \mathrm{~cm}$. Note that the geoid from Saitama to the Kashima-Nada Sea varies by the amount of $5 \mathrm{~m}$ to $12 \mathrm{~m}$.

The height of geoid on land is about $40 \mathrm{~m}$ but it decreases to $30 \mathrm{~m}$ or lower toward the sea. Note that there is approximately a $5 \mathrm{~m}$ to $12 \mathrm{~m}$ change in the height of geoid along the track of measurement. 


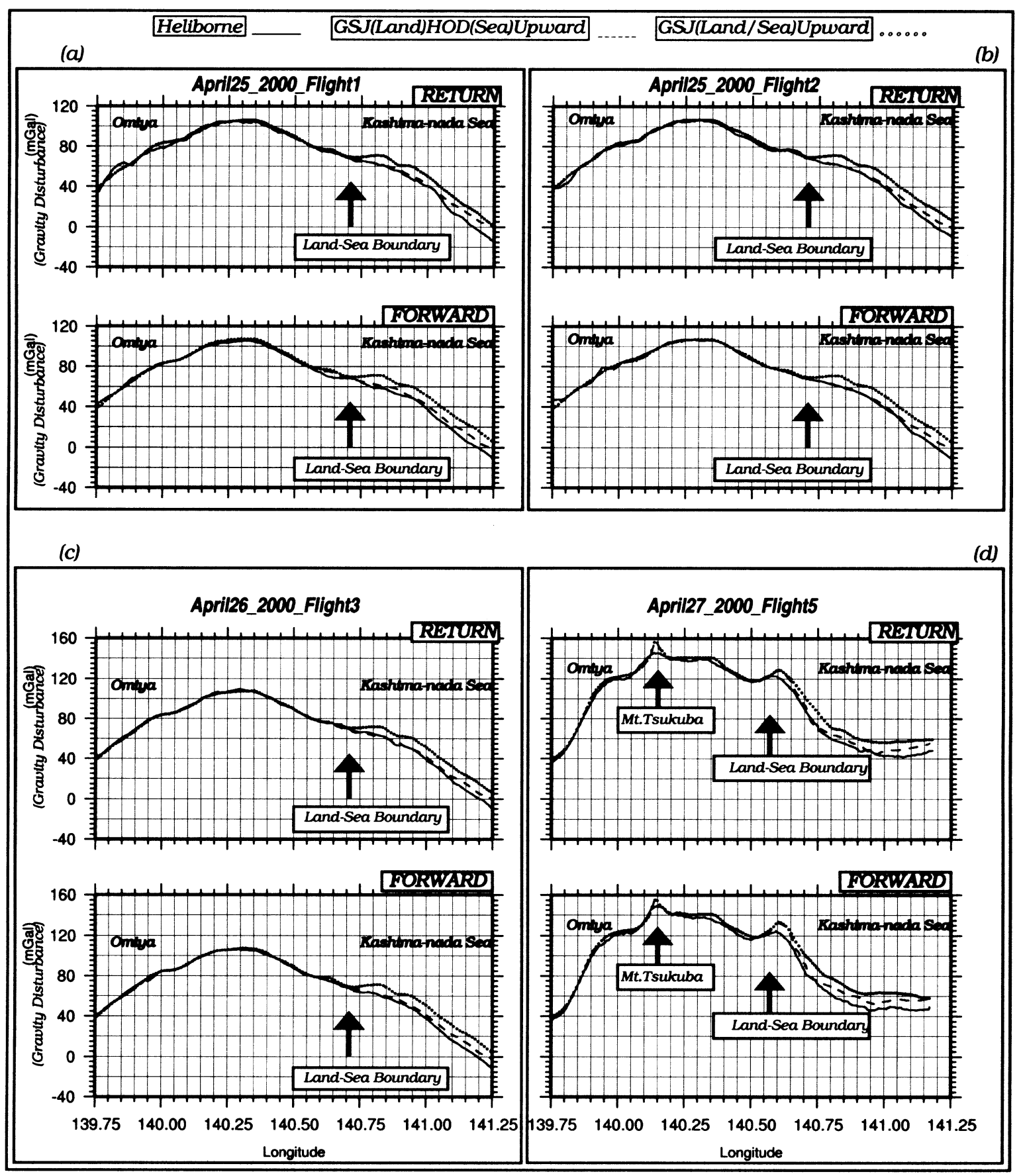

Fig. 10. Gravity disturbances obtained from the helicopter measurements conducted from 25 to 27 April 2000 together with the corresponding upward-continued ground/sea truth gravity disturbances from Saitama to the Kashima-Nada Sea. The results from Flights 1, 2, 3 and 5 are shown in (a), (b), (c) and (d), respectively. In each part the lower profile shows forward flight data and the upper profile shows backward flight data. Solid lines are gravity disturbances from helicopter measurements. Dotted lines are upward continued GSJ gravity disturbances (converted) covering both land and sea. Dashed lines are upward continued HOD marine gravity disturbances (converted) combined with GSJ land gravity disturbances (converted). The abscissa shows longitude (East) in degrees and the ordinate shows gravity disturbances in mgal. Land-to-sea boundaries and Mt. Tsukuba are indicated by arrows. An important finding from these results is that the GSJ marine data are by 17 to 20 mgal too large compared with the helicopter gravity data and that HOD data by 7 to $10 \mathrm{mgal}$ too large.

The accuracy of the ground/sea truth data depends not so much on the accuracy of measurement as on the degree of coverage of measurement. In the following discussions we emphasize a finding that the regional marine gravity is not harmonious with the gravity on the neighboring land. So, what matters is the average gravity over a wide area so that the effect of 'contouring error' may not be so important.

In the case of comparison of gravity we compare the air- borne gravity with the upward continued ground/sea truth gravity. First we adjust the bias of airborne gravity data within the land area so that they exactly agree with the upward-continued ground truth gravity disturbance. In this adjustment, if there should be any abnormal changes with either land gravity or airborne gravity, or both, it would be difficult to fit both gravity with each other. Fortunately, the upward-continued ground truth gravity disturbance and the 
FLIGHT -1

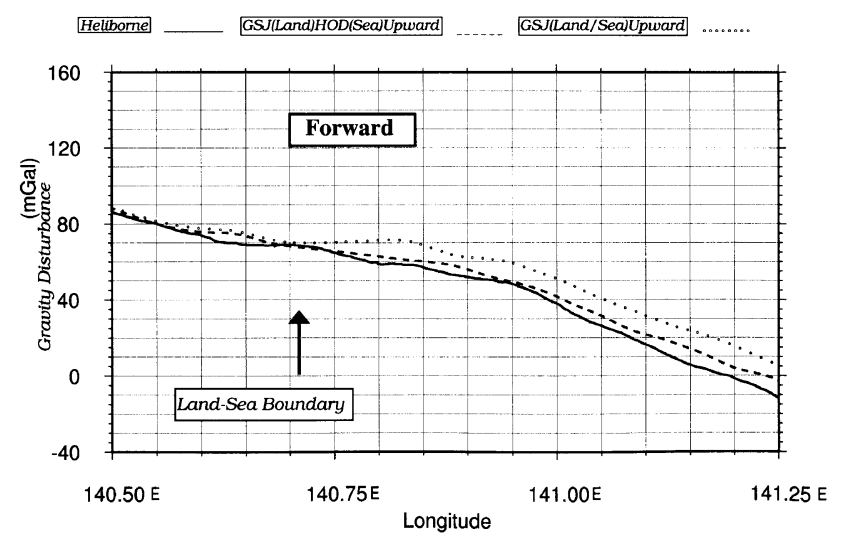

Fig. 11. Magnified features of gravity disturbances in the Kashima-Nada Sea for the case of Flight 1 (forward). Discrepancies among 'heliborne' (solid line), HOD (dashed line) and GSJ (dotted line) are obvious. Longitude is East-bound.

airborne gravity disturbance have agreed well within the land area in disregard of 2 to 3 mgal offsets observed in some places. After this adjustment we have found, contrarily, significant disagreements remaining with sea truth gravity. It is worth mentioning that the disagreement begins at the coastal line and is magnified seaward. Figure $10(a)(b)(c)(d)$ show the results. The ground/sea truth data in the area concerned are the data measured by GSJ and HOD. The ground truth data in this area are from GSJ only, but the sea truth data are from both GSJ and HOD, which are drawn separately for the profiles of Fig. 10(a)(b)(c)(d). In these figures the airborne gravity disturbances are drawn by solid lines and GSJ data and HOD data at sea are drawn by dotted and dashed lines respectively. Flight 1 and 2 were conducted on 25 April 2000, Flight 3 and 4 on 26 April 2000 and Flight 5 on 27 April 2000. Flight 4 was abandoned due to bad weather, as mentioned already. Note that the profiles do not cover all the tracks of flight as the data of start and end were abandoned because of the helicopter maneuvering. The actual range where gravity was determined is therefore between $139.75^{\circ} \mathrm{E}$ and $141.25^{\circ} \mathrm{E}$.

It is important that the divergence of data begins exactly at the coast; the GSJ marine data become larger than the helicopter data by the amount of roughly 17 to $20 \mathrm{mgal}$, and the HOD marine data become larger by the amount of roughly 7 to $10 \mathrm{mgal}$ as well. Flight 5 was on the southwestto-northeast track crossing Mt. Tsukuba, and the disagreement between helicopter gravity disturbance and sea truth gravity disturbance is as significant as in the previous cases. In Figs. 11 and 12 are shown magnified features of the results of measurement for the cases of Flight 1 (forward flight) and Flight 5 (forward flight), respectively, as examples. Discrepancies of measurements among 'heliborne', HOD and GSJ are obvious.

\section{An Additional Comment on the Accuracy of Gravity Measurement}

An experimental evaluation of the accuracy of our helicopter gravity measurement was reported in Segawa et al. (2000b). We will reproduce the result here to help better
FLIGHT -5

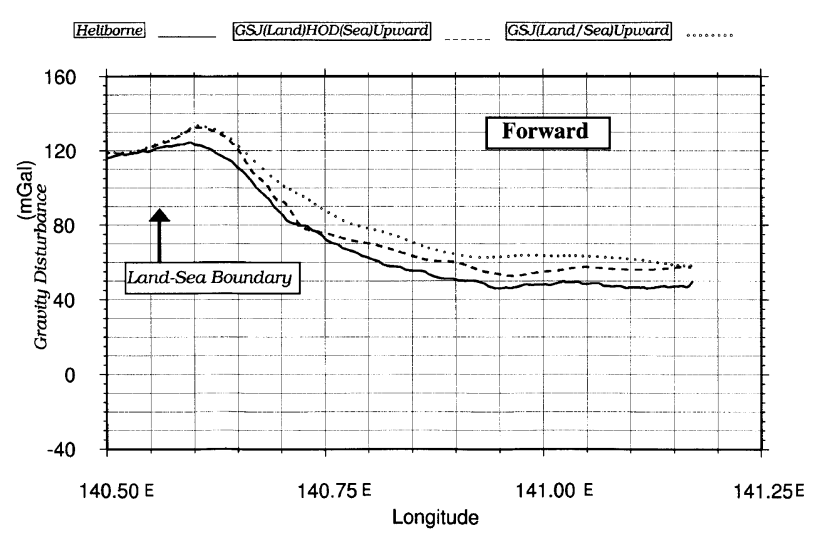

Fig. 12. Magnified features of gravity disturbances in the Kashima-Nada Sea for the case of Flight 5 (forward). Discrepancies among 'heliborne' (solid line), HOD (dashed line) and GSJ (dotted line) are obvious. Longitude is East-bound.

understand our paper. In Fig. 13 (upper profiles) are reproduced the gravity disturbances obtained from the gravity measurement in the case of Flight 3 conducted on 26 April 2000. These data are essentially the same as those used in Fig. 10(c). But, in the upper part of Fig. 13, the measured gravity profiles of the round trip flight are drawn together so that the repeatability of the measurement may be made clear. (Note that in Fig. 10(c) the forward or backward measured gravity profile is accompanied by forward or backward ground/sea truth gravity profile, respectively). Although the forward and backward profiles are drawn by the same black solid lines, their slight difference from each other is readable. If the difference is numerically evaluated, its bias difference averages $0.5 \mathrm{mgal}$ and the standard deviation is $1.5 \mathrm{mgal}$. In order to check how the shift of tracks which happened during the round trip affects gravity we made a comparison between the upward-continued ground/sea truth gravity disturbances on the forward and backward tracks of measurement. From Fig. 13 (lower profiles) it is seen that there is a slight disagreement in gravity profiles between the forward and backward tracks, though it is far less compared with the upper profiles. This may be a rough estimation of the effect from the deviation of the tracks on the changes of gravity. From this comparison it is found that most part of discrepancy of the measured gravity between the forward and backward tracks observed in Fig. 13 (upper profiles) is due to the intrinsic performance of the gravimeter itself. So, as a conclusion, it is reasonable to think that the bias error of $0.5 \mathrm{mgal}$ and the standard deviation $1.5 \mathrm{mgal}$ experimentally shown for the helicopter-borne gravity measurement is the overall accuracy of the gravimeter from the repeatability point of view. The authors think that the repeatability is the most important and persuasive factor by which to evaluate the accuracy of measurement. This is the reason why the authors dared not make any error assessment in advance.

\section{Conclusion}

The land and marine gravity in Japan have been correlated for the first time by the present study. It is usually 

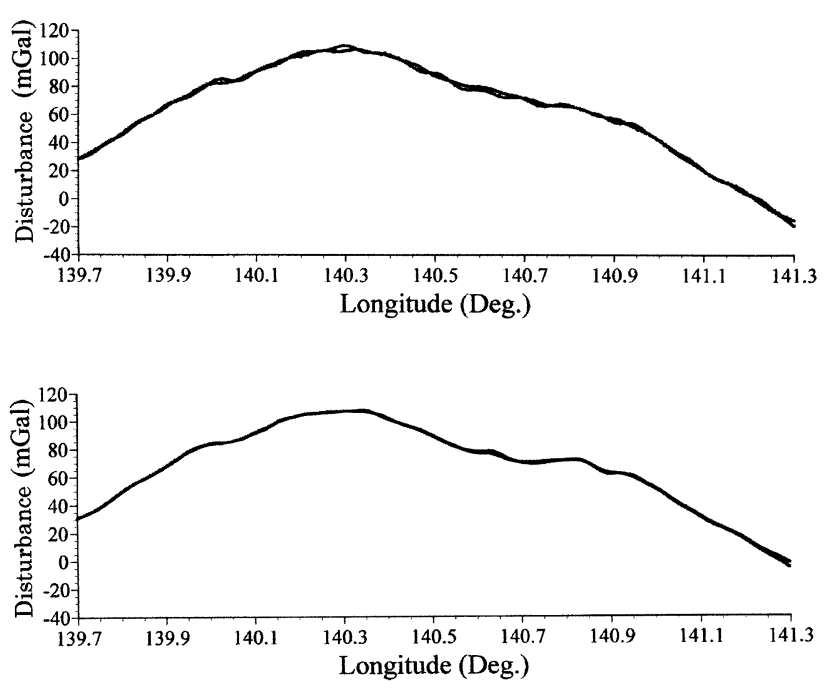

Fig. 13. (Upper) Gravity disturbances obtained from the gravity measurement in the case of Flight 3 conducted on 26 April 2000 from Saitama to Kashima-Nada Sea, Japan. The abscissa is east-bound longitude in degrees, and the ordinate gravity disturbance in mgal. One of the two solid lines is on the forward track and the other on the backward track. The data source is essentially the same as that in Fig. 10(c). (Lower) Upward-continued ground/sea truth gravity disturbances on the forward and backward tracks corresponding to the upper profiles. The gravity disturbances show how the shift of tracks during the round trip affected the gravity values.

the case that land and marine gravimetrists are separately positioned and hesitate to exchange information with each other. It is true that the marine gravity data involve errors much larger than those of land gravity data. But this fact has never been explicitly demonstrated. The largest problem against this may be the gravity void zones interfaced with the coasts.

By the present study using helicopter gravity measurement it has been clarified that the past marine gravity measurements around the Japanese Islands involve errors more than 10 mgals as revealed by the comparison with the neighbouring land gravity. This kind of comparison is feasible by the airborne gravimetry only. The marine gravity data in the Kashima-Nada Sea are those obtained in 1970's (HOD data) and at the beginning of 1980's (GSJ data). Since the largest problem with marine gravity measurements is the erroneous marine positioning, most gravity data at sea obtained before GPS became available may involve errors which we cannot overlook.

Our suggestion is that from geodetic and geophysical point of view it is necessary to revise old gravity data. The work for the revision in future should not be left to ships but be left to airplanes because the airborne gravimetry can provide gravity data as good as or better than the marine gravimetry and in addition the airborne gravimetry is able to make a seamless measurement from land to sea.

Acknowledgments. The authors would like to thank NEDO (New Energy and Industrial Technology Development Organization, Japan) for supporting our development of helicopter gravity measuring system from 1998 to 2000. Research funds provided by the Institute of Oceanic Research and Development, Tokai University and the Earthquake Research Institute, University of Tokyo are also acknowledged. Our thanks are also extended to Aero Asahi Corporation Japan and Tokimec Inc., Japan, for technical co-operation in helicopter navigation and manufacturing the gravimeter hard ware. Lastly, the authors would like to express thanks to the reviewers of our manuscript for giving us proper advices.

\section{References}

Brozena, J. M., The Greenland Aerogeophysics Project: Airborne gravity, topographic and magnetic mapping of an entire continent, Proc. IAG Symposium G3: Determination of the gravity field by space and airborne methods, Vienna, Aug. 1991, Springer-Verlag, New York, NY, 1992.

Brozena, J. M., J. LaBrecque, M. Peters, R. Bell, and C. Raymond, Airborne gravity measurement over sea-ice: the Western Weddel Sea, Geophys. Res. Lett., 17, 1941-1944, 1990.

Ganeko, Y., Y. Harada, and Y. Komatsu, Gravity measurements at sea in 1976, 1977 and 1978, Data Rep. Hydrogr. Obs., Series of Astro. Geod., 44-50, 1981.

Graf, A., Das Seegravimeter, Z. Instrumentenk., 60, 151-162, 1958.

Graf, A. and R. Schulze, Improvements on the sea gravimeter Gss2, J. Geophys. Res., 66, 1813-1821, 1961.

Gumert, W. R. and G. E. Cobb, Helicopter gravity measuring system, Proc. of the symp. on dynamic gravimetry, Fort Worth, Texas, 1970.

Hammer, S., Airborne gravity is here!, Geophysics, 48, 213-223, 1983.

Harlan, R. B., Eötvös correction for airborne gravimetry, J. Geophys. Res., 73, 4675-4679, 1968.

Kuroishi, Y., H. Ando, and Y. Fukuda, A new hybrid geoid model for Japan, GSIGEO2000, J. Geodesy, 76, 428-436, 2002.

LaCoste, L., Surface ship gravity measurements on the Texas A and M college ship, the Hidalgo, Geophysics, 24, 309-322, 1959.

LaCoste, L., N. Clarkson, and G. Hamilton, LaCoste-Romberg stabilized platform ship-board gravity meter, Geophysics, 32, 99-109, 1967a.

LaCoste, L., Measurement of gravity at sea and in the air, Rev. Geophysics, 5, 477-526, $1967 \mathrm{~b}$.

Miyazaki, T., Gravity survey in Kashima-Nada area, Geological Investigation of the Junction area of the Tohoku and Ogasawara Arcs, Cruise Rep., Geological Survey of Japan, No. 19, 87-90, 1984.

Sandwell, D. T. and G. Schubert, Geoid height-age relation from SEASAT altimeter profiles across the Mendocino fracture zone, J. Geophys. Res., 87, 3949-3958, 1982.

Segawa, J., H. Hasegawa, T. Ishihara, S. Sakuma, and M. Ishii, A preliminary study of the development of a helicopter-mounted gravity measuring system, Bull. Inst. Oceanic Res. and Develop., Tokai Univ., 21, 1-10, 2000a.

Segawa, J., S. Kusumoto, E. John Joseph, H. Hasegawa, S. Sekizaki, K. Takada, E. Nakayama, H. Suzuki, T. Ishihara, M. Komazawa, K. Yamamoto, and S. Sakuma, Airborne gravity measurement system by use of a helicopter, J. Geodetic Soc. Japan, 46, 223-229, 2000 b.

Tomoda, Y. and H. Kanamori, Tokyo surface ship gravity meter $\alpha-1, J$. Geodetic Soc. Japan, 7, 116-145, 1962.

Thompson, L. G. D., Airborne gravity meter test, J. Geophys. Res., 64, 488-492, 1959.

Thompson, L. G. D. and L. J. B. LaCoste, Arial gravity measurements, J. Geophys. Res., 65, 305-322, 1960.

Tsuboi, C., Y. Tomoda, and H. Kanamori, Continuous measurement of gravity on board a moving surface ship, Proc. Japan Academy, 37, 571576, 1961.

Vening Meinesz, F. A., Theory and practice of pendulum observations at sea, Publ. Neth. Geod. Comm., Waltman, Delft, 1929.

Vening Meinesz, F. A., Theory and practice of pendulum observations at sea, part II,Publ. Neth. Geod. Comm., Waltman, Delft, 1941.

J. Segawa (e-mail: jsegawa@herb.ocn.ne.jp), M. Komazawa, K. V. Kumar, E. Nakayama, E. J. Joseph, S. Kusumoto, K. Onodera, and Y. Kuroishi 